\title{
Foreign-trained physicians need residency spots
}

The federal government is spending \$4 million over the next 3 years to bring more foreign-trained doctors into Canada's professional fold in the hope of alleviating the shortage of physicians. But the Medical Council of Canada (MCC) says residency spots are still lacking.

Most of the money will be spent on expanding assessment and training, and developing national standards for testing and licensing (CMA7 2003;168[9]: 1119-23). In concrete terms, the funding is expected to bring at least 100 international medical graduates (IMGs) into the health system.

But the key obstacle IMGs now face is the lack of postgraduate positions, said Dr. Dale Dauphinee, executive director of the MCC and co-chair of a $\ddot{\vec{\sigma}}$ federal task force on IMG licen$\bigcirc$ sure. At least 600 IMGs have al- ready passed provincial medical exams, but can't get residency placements. "I'm glad to have [the funding] ... but increasing capacity still needs work," Dauphinee said. "I'm still concerned that we don't have enough to cover the training."

Dauphinee spoke at a Mar. 1 meeting in Calgary of the Canadian Taskforce on Licensure of IMGs.

Licensed foreign-trained physicians represent an estimated $23 \%$ of Canada's medical working force. "The contribution has been huge," said task force cochair Dr. Rodney Crutcher, Alberta's IMG program director. "One of the challenges for us is to assess the skills of these docs and to do it in a way that is fair, that is transparent."

Currently, each of the 10 provinces and 3 territories has its own medical systems and professional requirements for li- censing, resulting in often conflicting policies that IMGs must sort through.

The MCC will get $\$ 554000$ to support a consortium that will identify and promote common screening criteria for IMGs. It will also evaluate progress, and provide an online self-assessment and orientation program.

Three-quarters of the $\$ 4$ million will be used to help the provinces and territories expand assessment programs for unlicensed IMGs.

In Quebec, the funding may not be enough to mitigate a current shortfall of 1000 doctors. Quebec recruited 64 foreign doctors on its own last year. Meanwhile, Ontario faces a shortage of up to 1500 physicians.

"Work is being done there, but for sure, work isn't complete," said Crutcher. - Dina O'Meara, Calgary

\section{INTERnational DeVelopment}

\section{"Changing lives one village at a time"}

$\triangleright$ In some of the most remote regions of Tanzania, women give birth alone at home despite the availability of medical clinics. is Canadian Physicians for Aid and Relief (CPAR) is helping to $\vec{a}$ change that - and in the process improve the infant mor-

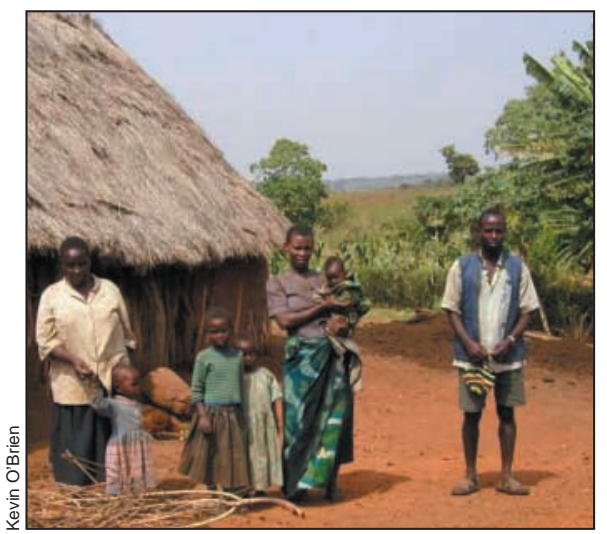

Local people bring new resources and hope to Gelamock, Tanzania. tality rate, which now stands at 104 death's per 1000 live births.

CPAR's executive director recently returned from Tanzania's maternal/child health program, a cooperative venture with the Society of Gynaecologists and Obstetricians of Canada. "We look at the root causes of problems," says Kevin O'Brien.

CPAR encourages sustainable development at the grass roots level in 4 African countries (www.cpar.ca). Its goal is to produce long-term results by training indigenous workers to help themselves. HIV/AIDS counselling staff are trained in Uganda, agricultural eduation is offered in Ethiopia and, in Malawi, local residents learn how to fight drought through soil and water conservation. CPAR began when Dr. - Ben Hadaway, CMAJ
Mark Doidge responded to the waves of immigrants fleeing the 1984 famines in Ethiopia. Over the next 20 years, it expanded to Malawi, Uganda, and now Tanzania.

CPAR also educates Canadian children through a 10-lesson curriculum on building healthy communities and runs the Plant a Tree program in Africa.

CPAR receives $76 \%$ of its $\$ 3.5$ million budget from the Canadian International Development Agency, with the remainder coming from private donors, $40 \%$ of whom are doctors. Only $9 \%$ of funding is spent on administrative costs.

CPAR chairperson Dr. Diana Lacaille agrees their work is only the tip of the iceberg. "It doesn't matter," she says. "We're changing lives one village at a time." 